\title{
Article \\ Effects of Combined Potassium and Organic Fertilizer Application on Newhall Navel Orange Nutrient Uptake, Yield, and Quality
}

\author{
Mingxia Wen ${ }^{1}$, Ji Zhang ${ }^{2}$, Yongqiang Zheng ${ }^{2}$ and Shilai $\mathrm{Yi}^{2, *}$ \\ 1 Zhejiang Citrus Research Institute, Taizhou 318020, China; wenmx198@126.com \\ 2 National Citrus Engineering Research Center, Citrus Research Institute, Southwest University, \\ Chongqing 400715, China; zhang_ji00@163.com (J.Z.); zhengyq@cric.cn (Y.Z.) \\ * Correspondence: yishilai@swu.edu.cn
}

Citation: Wen, M.; Zhang, J.; Zheng, Y.; Yi, S. Effects of Combined Potassium and Organic Fertilizer Application on Newhall Navel Orange Nutrient Uptake, Yield, and Quality. Agronomy 2021, 11, 1990. https://doi.org/10.3390/ agronomy11101990

Academic Editor: Hans-Werner Olfs

Received: 5 August 2021

Accepted: 28 September 2021

Published: 30 September 2021

Publisher's Note: MDPI stays neutral with regard to jurisdictional claims in published maps and institutional affiliations.

Copyright: () 2021 by the authors. Licensee MDPI, Basel, Switzerland. This article is an open access article distributed under the terms and conditions of the Creative Commons Attribution (CC BY) license (https:// creativecommons.org/licenses/by/ $4.0 /)$.

\begin{abstract}
In this study, we investigated the effects of the combined application of different doses of potassium and organic fertilizers on the nutrient uptake, yield, and quality of Newhall navel oranges (Citrus sinensis Osb. cv.). The citrus trees were treated with potassium fertilizer alone or with one of three combinations of organic and potassium fertilizers. Spring shoots, autumn shoots, and fruit were collected when they reached maturity, and the relevant indexes were determined by conventional methods. The soil carbon flux was measured $15,35,65$, and 95 days after fertilizer application by a soil gas flux measuring instrument. The results showed that the dry weights of leaves and twigs of the spring shoots were $43.1 \%$ and $99.8 \%$ higher in the OM15+K05-treated (15 kg organic manure and $1.05 \mathrm{~kg}$ potassium sulfate per plant) than in the $\mathrm{OM} 0+\mathrm{K} 25$-treated $(1.25 \mathrm{~kg}$ potassium sulfate per plant) plants, respectively. Combined potassium and organic fertilizer application helped the shoots and fruits to absorb more mineral nutrients. As a result, the fruit yield increased, fruit surface color improved, and skin thickness became thinner. The internal quality of the fruit was also improved by the combination of different potassium fertilizers and organic fertilizers. The fruit quality was optimal for the OM10+K15-treated plants. The recommended doses of organic and potassium sulfate fertilizers for Newhall navel orange orchards with purple paddy soil in southwestern China are $5-10 \mathrm{~kg} / \mathrm{plant}$ and $1.15-1.20 \mathrm{~kg} / \mathrm{plant}$, respectively.
\end{abstract}

Keywords: citrus; dry weights; mineral nutrients; soil improvement; quality improvement

\section{Introduction}

Citrus is an economically important crop in China. China's citrus yield reached 41.3 million tons in 2018, accounting for $16.1 \%$ of China's total fruit yield; however, citrus production still suffers from low yields per unit area, varying fruit quality, and low yield of high-quality fruits. There is therefore a pressing need to develop effective approaches to improve citrus yield and quality.

The elements nitrogen, N, phosphorus, $\mathrm{P}$, and potassium, K, are widely found in the plant kingdom and are necessary for plant growth. $\mathrm{K}$ is taken up very efficiently and longdistance transport occurs in the xylem and phloem throughout the plant. $\mathrm{K}$ is involved in all aspects of plant growth and has many different functions [1]. By adjusting plant water requirements through influencing the transpiration process [2], $\mathrm{K}$ plays a key role in the transport of photosynthates, the regulation of stomatal physiological mechanisms, the synthesis of carbohydrates [3], and is directly related to the regulation of the cell osmotic potential to minimize stress responses [4]. K also has an activator role for various enzymes, including synthetases, phosphokinases, nitrate reductases, and asparaginases in plants [5]. Therefore, potassium plays a vital role in fruit development, and in enhancing fruit size, color, and flavor [6]. Citrus, with its long growth cycle, is a nutrient-demanding fruit tree, and is highly responsive to applied nutrients in the form of fertilizers. The growth 
of citrus fruit removes an abundance of $K$, more than any other nutrient [7]; hence, a deficiency of $\mathrm{K}$ severely affects the fruit quality, as well as the final yield, of citrus. It is worth emphasizing that the leaching of $\mathrm{K}$ is a very common problem in orchards because of the humid conditions of the citrus planting area [8]. Moreover, excessive K application decreases the economic return and had no positive effects on fruit yield $[9,10]$.

Ashkevari showed that $\mathrm{K}$ fertilizer application increased citrus fruit partial quality parameters and decreased the ratio of soluble solids/titrable acidity (TSS/TA) and fruit water, but high levels of potassium fertilizer can reduce fruit yield [8]. Different $\mathrm{K}$ rates showed similar directions in regulating citrus vegetative growth, but TSS and TA varied with changes in $\mathrm{K}$ concentration [11]. Fruit yield and quality can also be affected by different forms of $\mathrm{K}^{+}\left(\mathrm{KNO}_{3}, \mathrm{KCl}\right.$, and $\left.\mathrm{K}_{2} \mathrm{SO}_{4}\right)$, but the changes are not completely consistent [12]. Therefore, the application method of $\mathrm{K}$ fertilizer should be further explored according to climate characteristics, variety characteristics, and consumption demand in practice. Only through appropriate $\mathrm{K}$ nutrition management can the improvement of fruit quality [13] and tree nutrient absorption [14] be achieved.

Over the years, large-scale application of mineral fertilizer has caused groundwater and environmental pollution through leaching and volatilization, and has also posed risks to soil biodiversity and heavy metal contents [15]. This situation can, however, be improved through the adoption and continuous use of organic fertilizer [16,17].

Organic fertilizer is a carbon-containing material of plant and/or animal origin, applied to soil for the primary function of providing plant nutrients. The application of organic fertilizer can provide essential elements for plant growth, improve soil physical and chemical properties, redeem soil microbial diversity and nutrient supply capacity in old orchards, and reduce the greenhouse effect [18]. The application of organic fertilizers to a sweet orange orchard significantly increased the number of fruit and average weight of fruit [19]. The appropriate combination of organic fertilizer and mineral elements to promote the absorption of nutrients, improving the yield and quality of crops, has also been generally regarded as an effective practice. Compared to applying mineral fertilizers, the improved management of $\mathrm{N}, \mathrm{P}$, and $\mathrm{K}$ fertilizer with organic fertilizer has contributed to improved vegetative growth, nitrogen and potassium uptake, and the accumulation of sugar content and vitamin $C$ in fruit [20]. Organic compounds combined with potassium fertilizer are also conducive to improve tree nutritional status or fruit quality for pineapples and pears. However, concerning citrus, there have been few reports on the effects of a combination of organic fertilizer and $\mathrm{K}$ on nutrient absorption and fruit quality.

On the other hand, extensive management of citrus orchards, unscientific fertilization, and low fruit quality are the major obstacles to the development of the citrus industry in China. Therefore, we chose old citrus orchards with poor site conditions to carry out the combined experiment of $\mathrm{K}$ and organic fertilizer. The specific objectives of this study were to: (1) investigate the effects of combined $\mathrm{K}$ with organic fertilizer on the dry matter accumulation and nutrient uptake of shoots and fruit; (2) compare the performance of different treatments on fruit quality parameters; and (3) select the optimal combination mode of $\mathrm{K}$ and organic fertilizer.

\section{Materials and Methods}

\subsection{Test Site and Materials}

The experiment was conducted from 2018 to 2019 in a Newhall navel orange (Citrus sinensis Osbeck cv. Newhall) orchard at Tianhe Agricultural Development Co., Wusheng County, Guang'an City, Sichuan Province, China $\left(30^{\circ} 41^{\prime} \mathrm{N}, 106^{\circ} 37^{\prime} \mathrm{E}\right.$; average elevation, $314 \mathrm{~m}$ ). The region features a subtropical monsoon climate, with an annual mean temperature of $18{ }^{\circ} \mathrm{C}$, annual mean sunshine duration of $1181.1 \mathrm{~h}$, and annual mean rainfall of $1087 \mathrm{~mm}$. The Newhall navel orange trees for testing were planted on ridges in 2012. They were grafted on trifoliate orange (Poncirus trifoliata (L.) Raf.) rootstocks, spaced $3 \mathrm{~m} \times 4 \mathrm{~m}$. The orchard was transformed from a paddy field with homogeneous purple soil, which had a soil $\mathrm{pH}$ of 5.51 , soil organic matter content of $16.07 \mathrm{~g} \cdot \mathrm{kg}^{-1}$, soil total nitrogen of 
$49.58 \mathrm{mg} \cdot \mathrm{kg}^{-1}$, soil available phosphorus of $8.35 \mathrm{mg} \cdot \mathrm{kg}^{-1}$, and soil available potassium of $78.79 \mathrm{mg} \cdot \mathrm{kg}^{-1}$, indicating medium and low levels of fertility. The soil was sampled at depths of $0-30 \mathrm{~cm}$ of the soil layer for the above data analysis.

\subsection{Experimental Design}

The experimental design for the combined potassium and organic fertilizer application is shown in Table 1. The organic fertilizers in each treatment were applied together as the base fertilizer in March. The organic fertilizer (Shanxi Shangluo Yongli Biological Technology Co., Ltd., Shangluo, Shanxi, China) used in this study had a $\mathrm{pH}$ of 6.4, moisture content of $26 \%$, organic matter content of $47.1 \%$, nitrogen content of $0.94 \%$, phosphorus pentoxide $\left(\mathrm{P}_{2} \mathrm{O}_{5}\right)$ content of $0.05 \%$, and potassium oxide $\left(\mathrm{K}_{2} \mathrm{O}\right)$ content of $0.51 \%$. The potassium fertilizer (agricultural potassium sulfate, State Development \& Investment Xinjiang Lop Nur Potash Corporation), Kuerle, Xinjiang, China) had a $\mathrm{K}_{2} \mathrm{O}$ content of $51 \%$. The nitrogen fertilizer (urea, Sichuan Tianhua Co., Ltd., Luzhou, Sichuan, China.) had a nitrogen content of $47 \%$ ). The phosphorus fertilizer (calcium-magnesium phosphate, Hubei Yuhui Chemical Co., Ltd., Xiangyang, Hubei, China.) had a $\mathrm{P}_{2} \mathrm{O}_{5}$ content of $12 \%$.

Table 1. Experimental design and treatment combination of potassium and organic fertilizers.

\begin{tabular}{|c|c|c|c|c|c|c|c|}
\hline \multirow{2}{*}{ Treatment } & \multicolumn{4}{|c|}{ Annual Fertilizer Dose $\left(\mathrm{kg} \cdot\right.$ plant $\left.^{-1}\right)$} & \multicolumn{3}{|c|}{$\begin{array}{l}\text { Corresponding Pure Nutrient } \\
\text { Content }\left(\mathrm{kg} \cdot \text { plant }^{-1}\right)\end{array}$} \\
\hline & $\begin{array}{l}\text { Organic } \\
\text { Fertilizer }\end{array}$ & Urea & $\begin{array}{c}\text { Calcium-Magnesium } \\
\text { Phosphate }\end{array}$ & $\begin{array}{l}\text { Potassium } \\
\text { Sulfate }\end{array}$ & $\mathbf{N}$ & $\mathrm{P}_{2} \mathrm{O}_{5}$ & $\mathrm{~K}_{2} \mathrm{O}$ \\
\hline $\mathrm{OM} 0+\mathrm{K} 25$ & 0 & 1.50 & 2.50 & 1.25 & 0.705 & 0.300 & 0.638 \\
\hline $\mathrm{OM} 5+\mathrm{K} 20$ & 5 & 1.50 & 2.50 & 1.20 & 0.752 & 0.303 & 0.638 \\
\hline OM10+K15 & 10 & 1.50 & 2.50 & 1.15 & 0.799 & 0.305 & 0.638 \\
\hline OM15+K05 & 15 & 1.50 & 2.50 & 1.05 & 0.846 & 0.308 & 0.612 \\
\hline
\end{tabular}

Note: OM0+K25, $0 \mathrm{~kg}$ organic manure and $1.25 \mathrm{~kg}$ potassium sulfate per plant; OM5+K20, $5 \mathrm{~kg}$ organic manure and $1.20 \mathrm{~kg}$ potassium sulfate per plant; OM10+K15, $10 \mathrm{~kg}$ organic manure and $1.15 \mathrm{~kg}$ potassium sulfate per plant; $\mathrm{OM} 15+\mathrm{K} 05,15 \mathrm{~kg}$ organic manure and $1.05 \mathrm{~kg}$ potassium sulfate per plant.

Seventeen Newhall navel orange trees in the same row with a moderate size and nearly the same growth rate were selected for each treatment before the experiment, and the trees at the beginning and end of the row acted as buffers (not sampled). Three replications were conducted for each treatment, with five trees in each replication. Fertilizers were applied in March, July, and October of each year, and the ratios of potassium sulfate, urea, and calcium-magnesium phosphate fertilizers in these three fertilizer applications were 0.5:1:0.5, 1:1:0.5, and 1:0.5:1, respectively. Before fertilizer application, two symmetrical furrows $(1.0 \mathrm{~m} \times 0.2 \mathrm{~m} \times 0.2 \mathrm{~m}$ each) were dug along the driplines of the crown of each tree (fertilizers were applied alternatively in the two furrows). After the fertilizers were mixed well with the excavated soil, they were backfilled into the furrows. Other cultivation management measures, such as pest and disease control, were conducted according to conventional production techniques.

\subsection{Sampling and Project Measurement}

\subsubsection{Shoot Collection and Nutrient Determination}

The newly sprouted spring shoots and autumn shoots during each test year were counted in September and December, respectively. Three shoots were collected from each of the eastern, western, southern, and northern parts of the crown of each tree. The shoots collected from five trees were mixed as one sample, and there were three samples (replications) from each treatment. The collected samples were immediately stored in ice boxes and quickly brought back to the laboratory for twig and leaf separation. After the fresh weights of the twigs and leaves were recorded, they were washed with deionized water and patted dry, cured at $105^{\circ} \mathrm{C}$ for $30 \mathrm{~min}$, and dried at $60-80{ }^{\circ} \mathrm{C}$ to a constant weight. After the dry weights of the twigs and leaves were recorded, they were pulverized 
and digested with the $\mathrm{H}_{2} \mathrm{SO}_{4}-\mathrm{H}_{2} \mathrm{O}_{2}$ method. The nitrogen, phosphorus, and potassium contents were determined using the semi-micro Kjeldahl method, molybdenum-antimony colorimetric method, and flame photometric method, respectively [21].

\subsubsection{Collection of Fruit Samples and Quality and Nutrient Determination}

The fruit yield of each plant was determined in the maturation period (December). Two fruits were collected from each of the eastern, western, southern, and northern parts of the crown of each tree (eight fruits from each tree). The fruits collected from five trees were pooled into one sample, and there were three samples (replications) for each treatment. The samples were immediately brought back to the laboratory. After the fruits were washed with deionized water and dried, the transverse and longitudinal diameters of each fruit were measured. The surface color difference of each fruit was measured by a portable color reader (CR-10, Konica Minolta, Tokyo, Japan). $L$ represents the brightness (higher $L$ corresponds to greater brightness), $a$ represents the difference between red and green colors (positive values represent the degree of redness, and a higher positive value indicates a darker red color; negative values represent the degree of greenness, and a smaller negative value indicates a darker green color), and $b$ represents the difference between yellow and blue colors (positive values represent the degree of yellowness, and a higher positive value indicates a darker yellow color; negative values represent the degree of blueness, and a smaller negative value indicates a darker blue color) [22]. The hardness of each fruit was measured with a fruit hardness tester (GY-4, Zhejiang Tope Instrument Co., Ltd., Hangzhou, Zhejiang, China). Before each fruit was cut and juiced, the pericarp thickness at its equator was determined with a vernier caliper. After juice extraction, the total soluble solids (TSS) content was determined with a digital refractometer (PAL-1, ATAGO, Japan), the titratable acid (TA) content was determined by titration with sodium hydroxide, the vitamin $\mathrm{C}\left(\mathrm{Vc}_{\mathrm{c}}\right)$ content was determined by titration with 2,6-dichlorophenol indophenol sodium, and the soluble sugar (SS) content was measured by anthrone colorimetry. After the quality indices were measured, the mixture of the pomace and juice (pulp) was crushed, and the peel was dried and ground to determine the nitrogen, phosphorus, and potassium contents in the pulp and peel.

\subsection{Nutrient Uptake by Shoots and Fruits}

The dry matter accumulation in the newly sprouted shoots in each test year was calculated based on the number of newly sprouted shoots in that year and the dry matter accumulation in the samples. The nutrient uptake by leaves and twigs was calculated from the dry matter accumulation and the nutrient content in the leaves and branches on a dry weight basis. The nutrients supplied from shoots to fruits (nutrient uptake by fruits) were calculated from the fruit fresh weight (fresh weight of peel and pulp), fruit (pulp and peel) water content, nutrient content in the pulp on a fresh weight basis, and nutrient content in the peel on a dry weight basis.

\subsection{Statistical Methods}

The data were statistically analyzed using Microsoft Excel (version 2010, USA Microsoft, Redmond, WA, USA) and SPSS (version 25.0, SPSS Japan Inc., Tokyo, Japan). Each treatment was repeated three times, and the significance of differences between treatments was assessed by Duncan's new complex extreme difference method (DMRT).

\section{Results}

3.1. Effects of Combined Potassium and Organic Fertilizer Application on Dry Matter Accumulation in and Nutrient Uptake by Newhall Navel Orange Shoots

3.1.1. Effect of Combined Potassium and Organic Fertilizer Application on Dry Matter Accumulation in Newhall Navel Orange Shoots

Figure 1 shows that the dry matter of spring shoot leaves was significantly higher $(43.1 \%)$ in OM15+K05-treated trees than in OM0+K25-treated trees, and that the dry matter accumulation in spring shoot leaves was lowest in OM5+K20-treated trees (351 g.plant ${ }^{-1}$ ). 
The accumulation of dry matter in autumn shoot leaves was highest in OM0+K25-treated trees $\left(329 \mathrm{~g} \cdot\right.$ plant $^{-1}$ ) and lowest in OM10+K15-treated trees, the latter being $37.8 \%$ lower than the former.

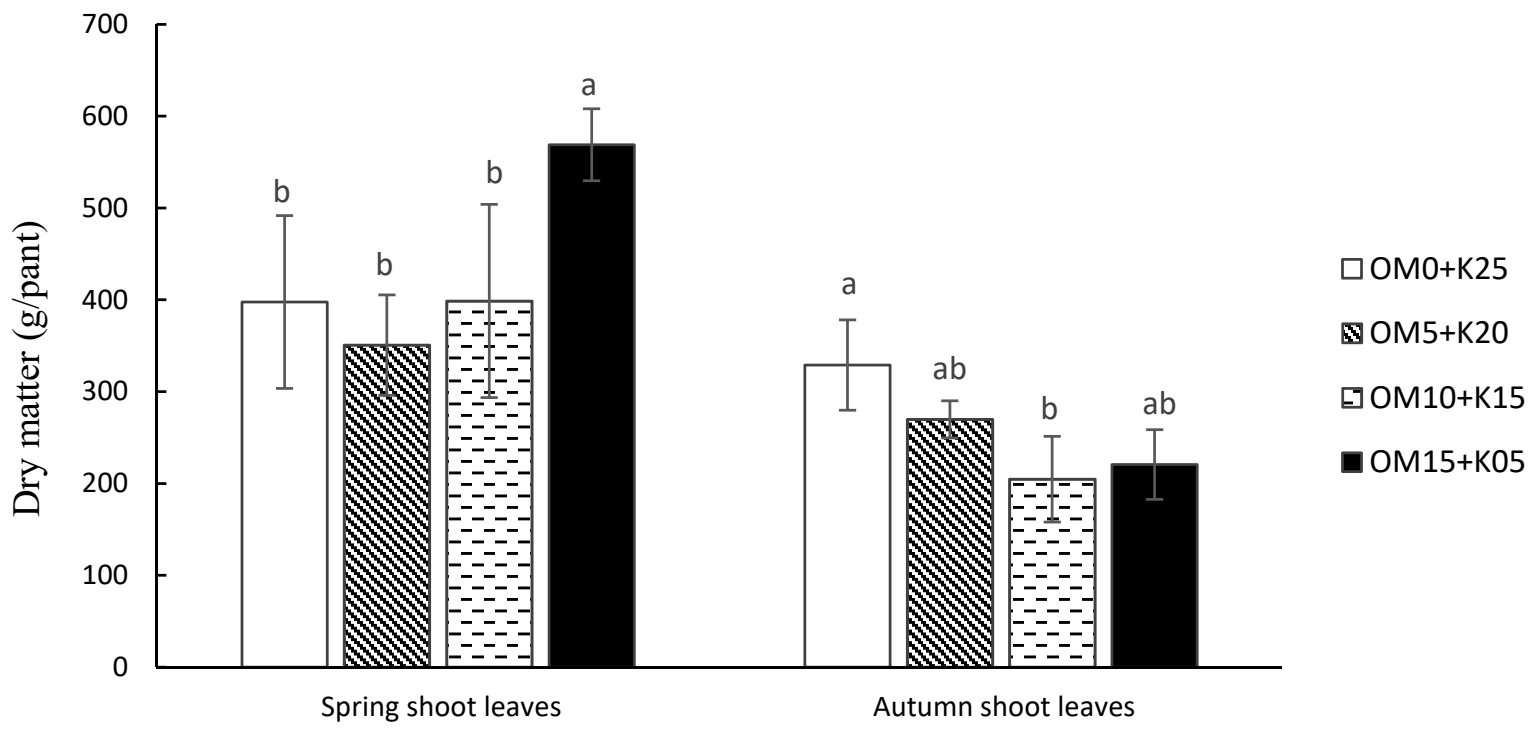

Figure 1. Effects of combined potassium and organic fertilizers on dry matter accumulation in Newhall navel orange leaves. Different letters above the column indicate significant differences at $p \leq 0.05$.

Combined potassium and organic fertilizer application had similar effects on dry matter accumulation in Newhall navel orange twigs and leaves (Figure 2). The dry matter accumulation in the branches of spring shoots was lowest in OM5+K20-treated trees and highest in OM15+K05-treated trees (significantly higher compared to the other treatments). The dry matter accumulation in the twigs of autumn shoots was not significantly different between treatments. These data show that OM15+K05 significantly promoted the growth and development of spring shoots, whereas $\mathrm{OM} 0+\mathrm{K} 25$ (potassium fertilizer application alone) resulted in the largest dry matter accumulation in autumn shoots, which may be related to the time and dosage of the potassium fertilizer and the dosage of organic fertilizer. The application of potassium fertilizer in July and October may more fully meet the large potassium demand during the growing period of the autumn shoots. Therefore, OM15+K05, which contained the highest proportion of organic fertilizer, was more conducive to the growth of spring shoots, while OM0+K25, which was composed of the potassium fertilizer alone, was more conducive to the growth of autumn shoots.

\subsubsection{Effect of Combined Potassium and Organic Fertilizer Application on Nutrient Uptake in Newhall Navel Orange Shoots}

Combined potassium and organic fertilizer application affected the nitrogen, phosphorus, and potassium contents in Newhall navel orange leaves and branches (Table 2). The potassium content in the leaves was 30.9\% and 26.1\% higher in OM15+K05-treated trees than in OM5+K20- and OM10+K15-treated trees, respectively, and was significantly different between treatments. The phosphorus content in the branches of spring shoots was significantly higher (by 12.7\%) in OM5+K20-treated trees than in OM0+K25-treated trees. The nitrogen content in the leaves of autumn shoots was significantly higher (by 11.0\%) in OM5+K20-treated trees than in OM15+K05-treated trees. The nitrogen, phosphorus, and potassium contents in the leaves of spring shoots were highest in OM15+K05-treated trees. The nitrogen, phosphorus, and potassium contents in leaves and branches of autumn shoots were the second highest in OM5+K20-treated trees. 


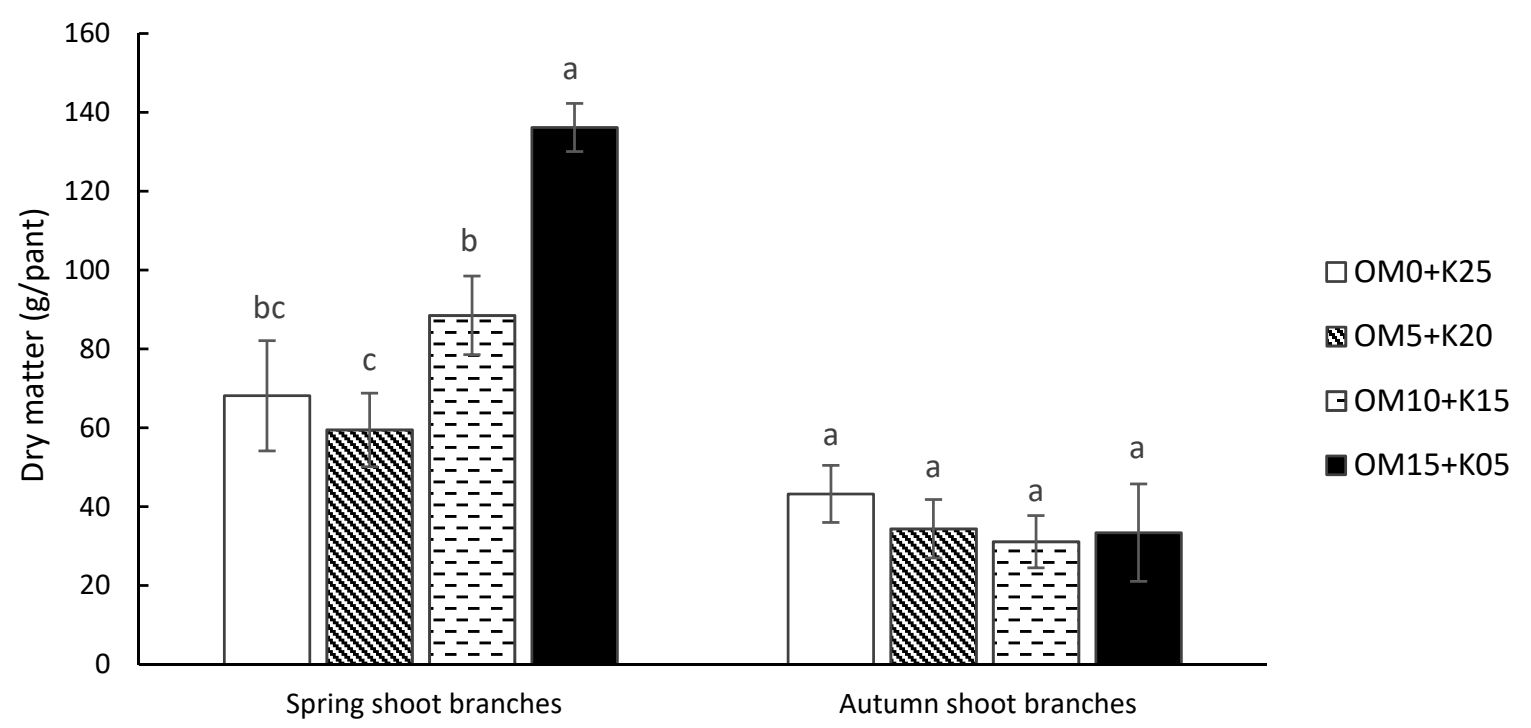

Figure 2. Effects of combined potassium and organic fertilizers on dry matter accumulation in Newhall navel orange branches. Different letters above the column indicate significant differences at $p \leq 0.05$.

Table 2. Effects of combined potassium and organic fertilizers on nutrient uptake in Newhall navel orange shoots.

\begin{tabular}{|c|c|c|c|c|c|c|c|}
\hline \multirow{2}{*}{ Shoot Type } & \multirow{2}{*}{ Treatment } & \multicolumn{3}{|c|}{ Leaves $\left(\mathrm{g} \cdot \mathrm{kg}^{-1}\right)$} & \multicolumn{3}{|c|}{ Branches $\left(\mathrm{g} \cdot \mathrm{kg}^{-1}\right)$} \\
\hline & & $\mathbf{N}$ & $\mathbf{P}$ & $\mathbf{K}$ & $\mathbf{N}$ & $\mathbf{P}$ & $\mathbf{K}$ \\
\hline & $\mathrm{OM} 0+\mathrm{K} 25$ & $27.20 \pm 1.86 a$ & $1.70 \pm 0.03 a$ & $13.25 \pm$ & $16.35 \pm 2.26 a$ & $1.73 \pm 0.09 b$ & $5.77 \pm 0.72 a$ \\
\hline Spring shoots & $\begin{array}{l}\text { OM5+K20 } \\
\text { OM10+K15 } \\
\text { OM15+K05 }\end{array}$ & $\begin{array}{l}27.57 \pm 1.31 \mathrm{a} \\
27.25 \pm 2.51 \mathrm{a} \\
29.85 \pm 1.80 \mathrm{a}\end{array}$ & $\begin{array}{l}1.66 \pm 0.07 a \\
1.71 \pm 0.18 a \\
1.72 \pm 0.08 a\end{array}$ & $\begin{array}{l}11.91 \pm 2.12 b \\
12.36 \pm 0.82 b \\
15.59 \pm 1.86 a\end{array}$ & $\begin{array}{l}18.27 \pm 0.88 a \\
16.72 \pm 2.33 a \\
17.59 \pm 1.10 a\end{array}$ & $\begin{array}{r}1.95 \pm 0.13 \mathrm{a} \\
1.72 \pm 0.23 \mathrm{~b} \\
1.91 \pm 0.12 \mathrm{ab}\end{array}$ & $\begin{array}{l}5.32 \pm 0.48 a \\
4.79 \pm 0.44 a \\
5.53 \pm 0.98 a\end{array}$ \\
\hline $\begin{array}{l}\text { Autumn } \\
\text { shoots }\end{array}$ & $\begin{array}{l}\text { OM0+K25 } \\
\text { OM5+K20 } \\
\text { OM10+K15 } \\
\text { OM15+K05 }\end{array}$ & $\begin{array}{c}19.77 \pm 1.47 \mathrm{ab} \\
20.73 \pm 0.85 \mathrm{a} \\
19.15 \pm 1.40 \mathrm{ab} \\
18.67 \pm 1.45 \mathrm{~b}\end{array}$ & $\begin{array}{l}1.74 \pm 0.13 a \\
1.60 \pm 0.16 a \\
1.67 \pm 0.22 a \\
1.61 \pm 0.21 a\end{array}$ & $\begin{array}{l}8.37 \pm 1.46 \mathrm{a} \\
8.46 \pm 0.42 \mathrm{a} \\
7.32 \pm 0.99 \mathrm{a} \\
8.64 \pm 1.02 \mathrm{a}\end{array}$ & $\begin{array}{l}10.73 \pm 0.97 \mathrm{a} \\
12.03 \pm 1.09 \mathrm{a} \\
12.01 \pm 0.93 \mathrm{a} \\
11.78 \pm 1.04 \mathrm{a}\end{array}$ & $\begin{array}{c}1.64 \pm 0.37 \mathrm{a} \\
1.50 \pm 0.19 \mathrm{a} \\
1.39 \pm 0.3 \mathrm{a} \\
1.51 \pm 0.3 \mathrm{a}\end{array}$ & $\begin{array}{l}5.95 \pm 1.60 a \\
5.38 \pm 1.13 a \\
4.88 \pm 0.69 a \\
5.39 \pm 0.96 a\end{array}$ \\
\hline
\end{tabular}

Data (means $\pm \mathrm{SE}, n=3$ ) followed by the different letters among treatments indicate significant differences at $p \leq 0.05$.

\subsection{Effect of Combined Potassium and Organic Fertilizer Application on Nutrient Uptake by Newhall Navel Orange Fruits}

The nitrogen content in the pulp and whole fruit showed similar patterns (Figure 3). It was higher in OM0+K25-treated trees for the pulp and whole fruit compared to other treatments, but was not significantly different between the other three treatments. Specifically, the nitrogen content was significantly higher in the pulp of OM0+K25-treated trees than in the pulp of OM5+K20-, OM10+K15-, and OM15+K05-treated trees (by $22.6 \%, 25.2 \%$, and $16.7 \%$, respectively), and the nitrogen content was significantly higher in the whole fruit of OM0+K25-treated trees than in the whole fruit of OM5+K20- and OM10+K15-treated trees (by $12.2 \%$ and $9.2 \%$, respectively). The nitrogen content in the peel was lowest in $\mathrm{OM} 5+\mathrm{K} 20$-treated trees and highest in OM10+K15-treated trees. The nitrogen content in the peel was not significantly different between different treatments.

Different combinations of potassium and organic fertilizers had significantly different effects on the phosphorus content in the pulp and peel (Figure 4). The pulp and whole fruit showed similar patterns. The phosphorus content in the pulp and whole fruit was significantly higher in OM15+K05-treated trees than in OM0+K25-treated trees (by 14.7\% and $13.2 \%$, respectively). The phosphorus content in the peel was significantly different between different treatments. The phosphorus content was significantly higher in the peel of OM15+K05-treated trees than in the peel of OM5+K20- and OM10+K15-treated trees (by $27.6 \%$ and $40.6 \%$, respectively), and the phosphorus content was significantly higher in the peel of OM0+K25-treated trees than in the peel of OM10+K15-treated trees. 


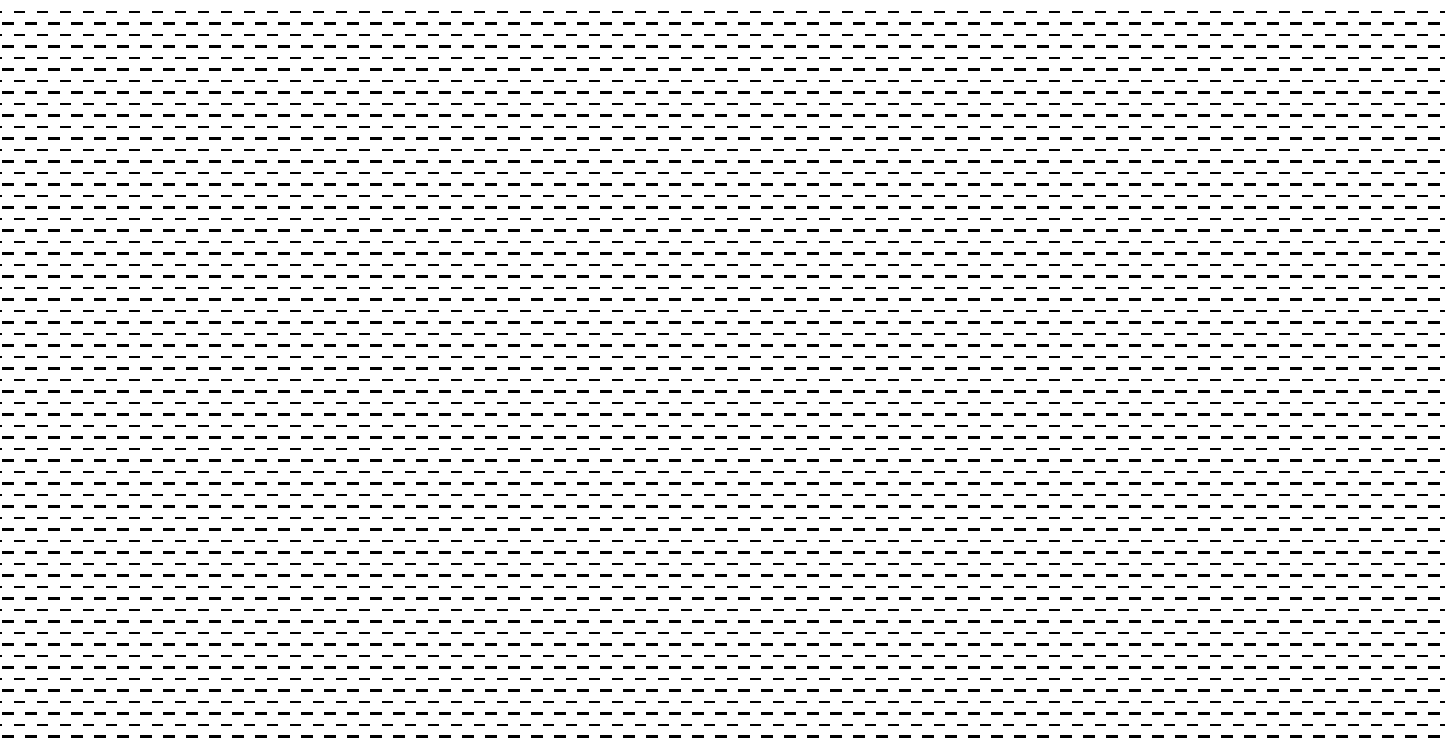

Figure 3. Effects of combined potassium and organic fertilizers on the $\mathrm{N}$ content in Newhall navel orange fruit. Different letters above the column indicate significant differences at $p \leq 0.05$.

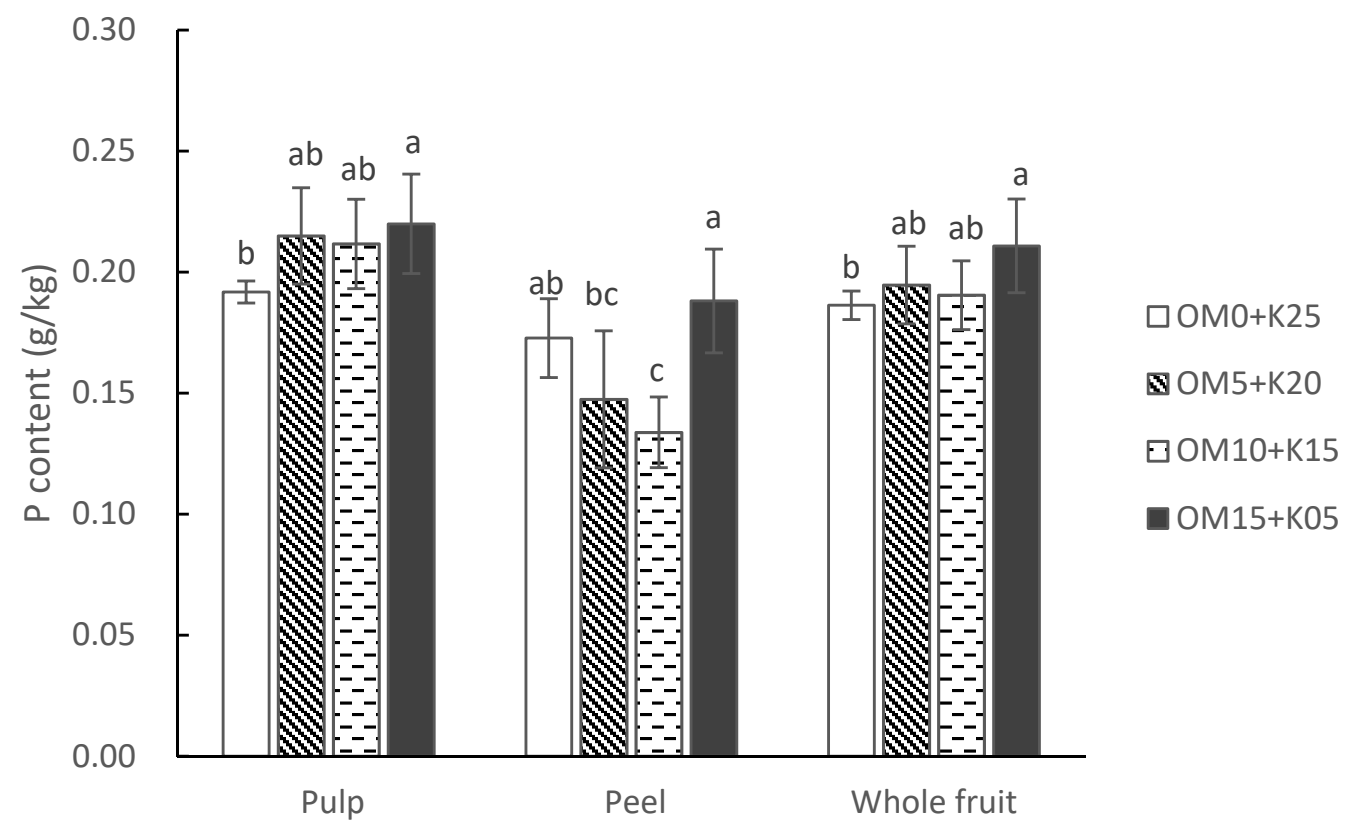

Figure 4. Effects of combined potassium and organic fertilizers on the P content in Newhall navel orange fruit. Different letters above the column indicate significant differences at $p \leq 0.05$.

Combined potassium and organic fertilizer application had similar effects on the potassium and nitrogen contents in fruits (Figure 5). The potassium content was highest in the peel of OM0+K25-treated trees, which was significantly higher $(31.1 \%)$ than the potassium content in the peel of OM5+K20-treated trees; however, the potassium content in the peel of OM5+K20-treated trees did not significantly differ from that of the other treatments. The potassium content in the pulp and whole fruit was not significantly different between treatments, although both were highest in $\mathrm{OM} 0+\mathrm{K} 25$-treated trees. 


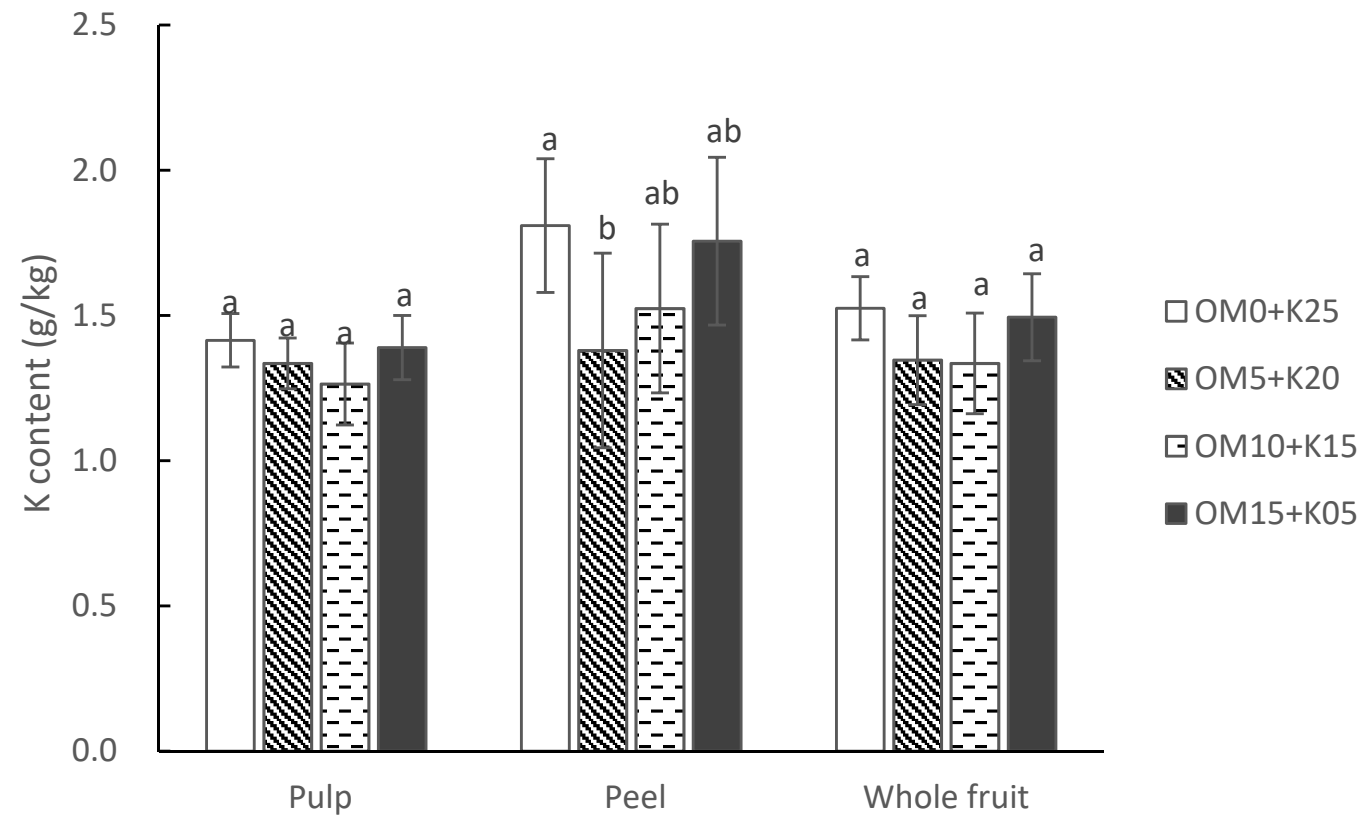

Figure 5. Effects of combined potassium and organic fertilizers on the K content in Newhall navel orange fruit. Different letters above the column indicate significant differences at $p \leq 0.05$.

3.3. Effect of Combined Potassium and Organic Fertilizer Application on Newhall Navel Orange Fruit Yield and Quality

3.3.1. Effect of Combined Potassium and Organic Fertilizer Application on Yield

The effect of combined potassium and organic fertilizer application on the Newhall navel orange yield is shown in Figure 6. The OM5+K20-treated trees had the highest yield, which was $2.2 \%$ higher than the yield of OM0+K25-treated trees. The OM15+K05treated trees had the lowest yield, which was significantly lower (by $42.8 \%$ ) than that of the OM5+K20-treated trees.

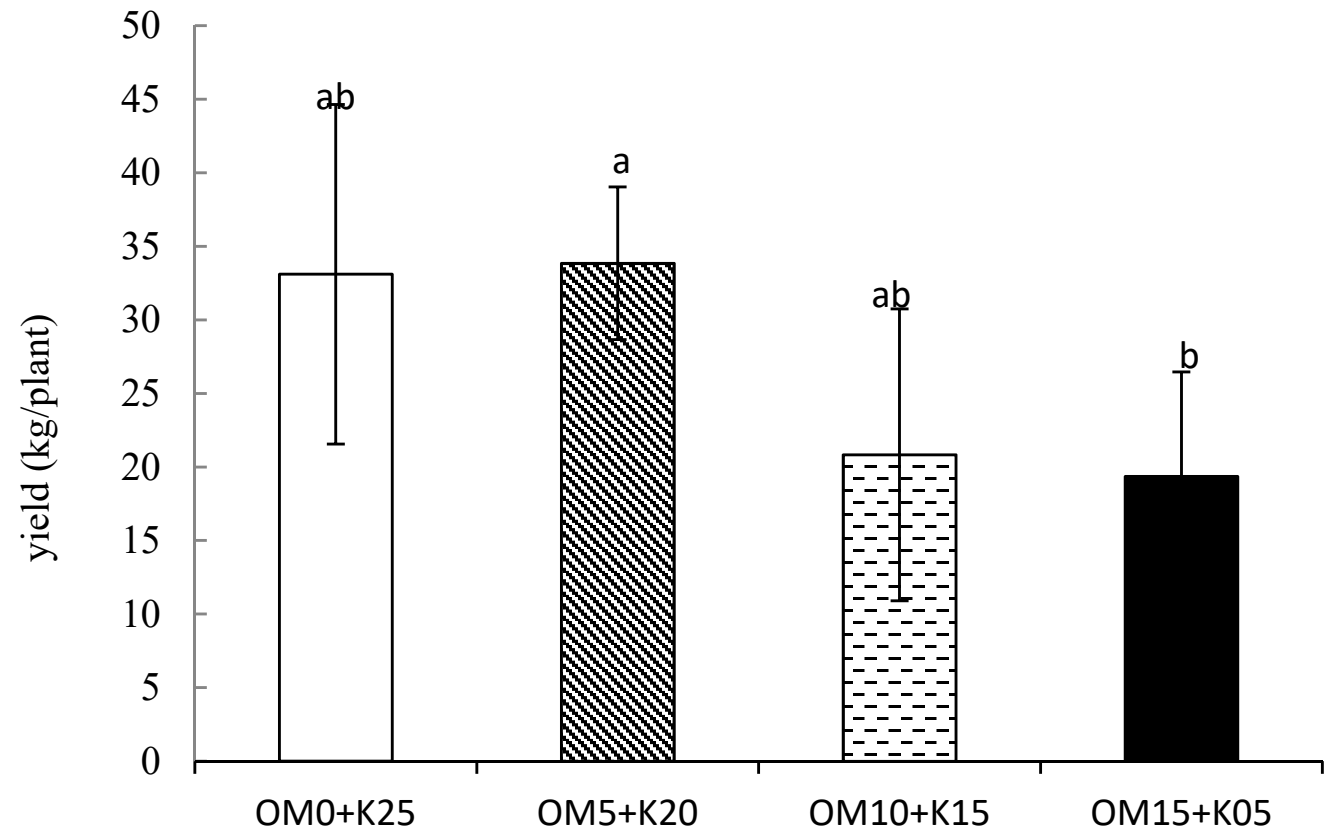

Figure 6. Effects of combined potassium and organic fertilizers on the Newhall navel orange yield. Different letters above the column indicate significant differences at $p \leq 0.05$. 
3.3.2. Effect of Combined Potassium and Organic Fertilizer Application on Newhall Navel Orange Fruit Quality

Combined potassium and organic fertilizer application had a significant effect on the Newhall navel orange fruit color (Table 3). The peel of the OM0+K25-treated trees had the highest brightness, which was significantly higher than those of the OM5+K20- and OM10+K15-treated trees. The redness of the peel was significantly higher in the three groups with both potassium and organic fertilizers than in the group with the organic fertilizer alone (OM0+K25). The redness was highest in OM10+K15-treated trees. The trend of yellowness of the peel $(b)$ was similar to that of the peel brightness. Specifically, the yellowness was highest in OM0+K25-treated trees, was significantly higher in OM0+K25and OM15+K05-treated trees than in OM10+K15-treated trees, and was not significantly different between the other treatments. The pattern in the level of pigmentation $(a / b)$ was consistent with the pattern of redness: $a / b$ was highest in OM10+K15-treated trees. This result suggests that combined potassium and organic fertilizer application at suitable doses can improve the color change and coloration of oranges and that the fruit coloration of Newhall navel oranges from OM10+K15-treated trees was the best.

Table 3. Effect of combined potassium and organic fertilizers on Newhall navel orange fruit color.

\begin{tabular}{ccccc}
\hline Treatment & $\mathbf{L}$ & $\mathbf{a}$ & $\mathbf{b}$ & $\mathbf{a} / \mathbf{b}$ \\
\hline OM0+K25 & $80.17 \pm 2.44 \mathrm{a}$ & $18.71 \pm 8.59 \mathrm{c}$ & $48.34 \pm 3.03 \mathrm{a}$ & $0.39 \pm 0.19 \mathrm{c}$ \\
OM5+K20 & $75.71 \pm 0.63 \mathrm{bc}$ & $27.26 \pm 1.56 \mathrm{ab}$ & $43.61 \pm 1.09 \mathrm{ab}$ & $0.63 \pm 0.04 \mathrm{~b}$ \\
OM10+K15 & $73.20 \pm 4.96 \mathrm{c}$ & $33.08 \pm 3.36 \mathrm{a}$ & $39.78 \pm 6.75 \mathrm{~b}$ & $0.86 \pm 0.21 \mathrm{a}$ \\
OM15+K05 & $77.81 \pm 1.54 \mathrm{ab}$ & $24.32 \pm 2.65 \mathrm{bc}$ & $46.90 \pm 2.73 \mathrm{a}$ & $0.52 \pm 0.08 \mathrm{bc}$ \\
\hline
\end{tabular}

Note: $\mathrm{L}$ is the lightness factor ranging from black (-L) to white (+L), a is the chromaticity coordinate ranging from green $(-a)$ to red $(+a)$ and, $b$ is the chromaticity coordinate ranging from blue $(-b)$ to yellow $(+b)$. Data (means $\pm \mathrm{SE}, n=3$ ) followed by the different letters among treatments indicate significant differences at $p \leq 0.05$.

The pericarp thickness of fruits was significantly lower in trees treated with combinations of potassium and organic fertilizers (OM5+K20, OM10+K15, and OM15+K05) than in the OM0+K25-treated trees (by 15.1\%, 21.3\%, and 19.7\%, respectively) (Figure 7). The pericarp thickness was thinnest in the OM10+K15-treated trees but was not significantly different between the OM5+K20-, OM10+K15-, and OM15+K05-treated trees. Therefore, combined potassium and organic fertilizer application reduced the pericarp thickness.

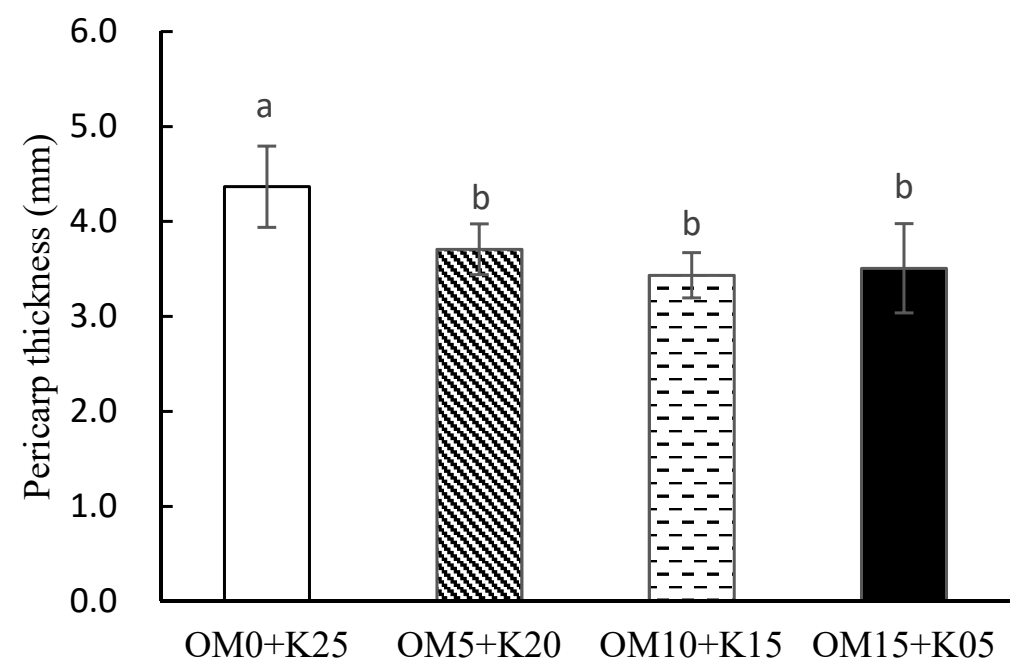

Figure 7. Effects of combined potassium and organic fertilizers on Newhall navel orange fruit pericarp thickness. Different letters above the column indicate significant differences at $p \leq 0.05$.

Compared to the $\mathrm{OM} 0+\mathrm{K} 25$ treatment, combined potassium and organic fertilizer application increased the TSS content in Newhall navel orange fruit to varying degrees 
(Table 4). The OM10+K15-treated trees had the highest TSS content in fruits, which was significantly higher $(7.7 \%$ higher) than that of the OM0+K25-treated trees. The OM5+K20treated trees had the lowest TA content and the highest TSS/TA ratio, but the differences were not significant. The OM10+K15-treated trees had the highest $\mathrm{Vc}_{\mathrm{c}}$ and SS content in the fruits, but the differences between treatments were not significant. Overall, OM10+K15treated trees had the best fruit quality, followed by the OM5+K20- and OM15+K05-treated trees, indicating that combined potassium and organic fertilizer application improves the intrinsic fruit quality of Newhall navel oranges.

Table 4. Effects of combined potassium and organic fertilizers on Newhall navel orange fruit intrinsic quality.

\begin{tabular}{cccccc}
\hline Treatment & $\begin{array}{c}\text { Total Soluble } \\
\text { Solids TSS (\%) }\end{array}$ & $\begin{array}{c}\text { Titratable Acid } \\
\text { TA (\%) }\end{array}$ & $\begin{array}{c}\text { Total Soluble } \\
\text { Solids/Titratable } \\
\text { Acid TSS/TA }\end{array}$ & $\begin{array}{c}\text { Vitamin C Vc } \\
\text { (mg/100 mL) }\end{array}$ & $\begin{array}{c}\text { Soluble Sugar SS } \\
\text { (\%) }\end{array}$ \\
\hline OM0+K25 & $11.14 \pm 0.72 \mathrm{~b}$ & $1.11 \pm 0.14 \mathrm{a}$ & $10.15 \pm 1.24 \mathrm{a}$ & $53.14 \pm 6.36 \mathrm{a}$ & $5.15 \pm 1.11 \mathrm{a}$ \\
OM5+K20 & $11.24 \pm 0.34 \mathrm{ab}$ & $0.95 \pm 0.15 \mathrm{a}$ & $11.99 \pm 1.66 \mathrm{a}$ & $56.53 \pm 2.58 \mathrm{a}$ & $5.16 \pm 0.23 \mathrm{a}$ \\
OM10+K15 & $12.00 \pm 0.19 \mathrm{a}$ & $1.09 \pm 0.22 \mathrm{a}$ & $11.32 \pm 1.93 \mathrm{a}$ & $58.50 \pm 6.41 \mathrm{a}$ & $6.19 \pm 1.09 \mathrm{a}$ \\
OM15+K05 & $11.48 \pm 0.79 \mathrm{ab}$ & $1.15 \pm 0.15 \mathrm{a}$ & $10.02 \pm 0.75 \mathrm{a}$ & $55.07 \pm 4.72 \mathrm{a}$ & $5.75 \pm 0.54 \mathrm{a}$ \\
\hline
\end{tabular}

Data (means $\pm \mathrm{SE}, n=3$ ) followed by the different letters among treatments indicate significant differences at $p \leq 0.05$.

\section{Discussion}

The soil conditions of citrus orchards in China are generally poor; however, organic fertilizer application is laborious and time consuming, while mineral fertilizer application is known to be effective [23]. Consequently, the overuse of mineral fertilizers and neglect of organic fertilizers are common in citrus orchards. The long-term application of a single type of mineral fertilizer can lead to reduced fruit quality, soil nutrient imbalance, and soil acidification and compaction, eventually reducing the soil nutrient supply and storage [24] Low fertilizer use efficiency further increases the amount of mineral fertilizer applied and leads to the loss of large amounts of nutrients and greater amounts of fertilizer waste, increasing the cost of crop production and the risk of agricultural environment pollution [25]. Rational organic fertilizer application can improve orchard soil conditions and fruit quality.

Combined potassium and organic fertilizer application promote dry matter accumulation and nitrogen, phosphorus, and potassium uptake in the spring shoots of Newhall navel orange trees.

The sprouting of sufficient high-quality spring and autumn shoots ensures the yield and quality of fruit in the coming year. Organic fertilizers could promote the sprouting of spring shoots in citrus trees, increase the chlorophyll content in these shoots, and make them more robust [26]. This study found that the dry matter accumulation in spring shoots was highest in the OM15+K05-treated trees, whereas the dry matter accumulation in autumn shoots was highest in the OM0+K25-treated trees. When autumn shoots sprout, the fruits are in the growth period, and the nutrients supplied to the trees are predominantly distributed to the fruits to satisfy their growth needs. Therefore, the low proportion of potassium fertilizer in the $\mathrm{OM} 15+\mathrm{K} 05$ treatment could not provide enough nutrients for the autumn shoots, resulting in a relatively low dry matter accumulation. Scientific and rational combinations of organic and mineral fertilizers can provide an adequate supply of nutrients to ensure Newhall navel orange tree growth, especially in periods when the trees grow vigorously and require large amounts of nutrients.

Rational use of organic fertilizer [27] and K fertilizer can promote the accumulation of biomass in crops. Our study found that the dry matter accumulation in the spring shoots was highest in the OM15+K05-treated trees, indicating that combined potassium and organic fertilizer application helped to change the unfavorable growth conditions and promote the growth of the citrus plants.

However, the dry matter accumulation in the autumn shoots was higher in the $\mathrm{OM} 0+\mathrm{K} 25-$ and $\mathrm{OM} 5+\mathrm{K} 20$-treated trees. This may be related to the functionality of organic 
fertilizers and $\mathrm{K}$ fertilizers. Nutrients in organic fertilizers are usually released gradually $[28,29]$, while the mineral fertilizer of potassium sulfate used in this study has rapid availability and can supply a large amount of $\mathrm{K}$ to trees during the rapid growth stage of the autumn shoots. This accelerated the accumulation of vegetative biomass in the autumn shoots. $\mathrm{K}$ is also involved in the process of allocating nutrients; it facilitates the transport of assimilates from the source (shoots) to the sink (fruits) [30], and hence promotes a rapid increase in fruit yield, as the period of rapid fruit expansion is also the period from germination to the ripening of the autumn shoots. Additionally, the fruit production of treatment $\mathrm{OM} 0+\mathrm{K} 25$ and $\mathrm{OM} 5+\mathrm{K} 20$ treatments was significantly higher than that of the $\mathrm{OM} 15+\mathrm{K} 05$ treatment, which was confirmed in this study. However, excessive application of $\mathrm{K}$ fertilizer is not conducive to the improvement of fruit quality [8].

Citrus trees have a long growth cycle with simultaneous vegetative growth and reproductive growth. The competition for nutrients between the autumn shoots and fruits is particularly intense because the autumn shoots sprout during rapid fruit enlargement [31]. Reproductive growth determines the yield and quality of fruit in the present year, and vegetative growth determines the fruit set in the coming year, thus ensuring that the trees absorb sufficient nutrients to support reproductive and vegetative growth, which is critically important. In this study, $\mathrm{N}, \mathrm{P}$, and $\mathrm{K}$ content in the shoots were higher in OM15+K05- and OM5+K20-treated trees, whereas the N, P, and K content in the fruits were highest in OM10+K15-treated trees, further indicating that combined potassium and organic fer-tilizer application can improve the nutrient uptake of orange trees.

Combined potassium and organic fertilizer application can improve fruit quality.

Omaima and Metwally reported that higher levels of soluble solids can be obtained in the fruit with $\mathrm{K}$ involvement in product transportation and protein-carbohydrate biosynthesis [32]. The application of organic fertilizer could improve the physical and chemical properties of soil [33], thus improving the fruit quality and yield of citrus [34]. Our results indicated that the application of K, along with organic fertilizer (OM10+K15 treatment), was effective in enhancing fruit TSS when compared to $\mathrm{K}$ applied alone. Although the TA did not change significantly, the solid acid ratio, vitamin C, and SS of the fruit were better, the skin thickness was significantly reduced, and the color of the fruit was improved. The results indicated that the fruit treated by OM10+K15 would be more preferred by consumers in China. Foregoing a previous study also found that using potassium fertilizer plus biofertilizer, as well as vinasse, improved the growth, nutritional status, and fruiting of mandarin trees compared to potassium fertilizer alone.

Previous studies have shown that the application of K alone increased TSS, but TA and rind thickness were also increased and the fruit flavor (TSS/TA) deteriorated for citrus fruit [8]. Contradictory opinions were also presented by Kinnow [35]. The reasons for this difference may be related to the different environmental conditions, methods, and objectives of $\mathrm{K}$ fertilizer use. Increasing organic fertilizer management could increase fruit TSS and reduce fruit acidity as well as fruit peel thickness [14]. Therefore, the application of $\mathrm{K}$ fertilizer should follow local conditions to avoid the inefficiency and environmental problems caused by blind use. The research on improving citrus quality by combining $\mathrm{K}$ with organic fertilizer presented in this study provides a positive reference for the application of $\mathrm{K}$ fertilizer and the improvement of citrus quality.

On the other hand, previous results have recommended a $\mathrm{K}$ dose of $1.5 \mathrm{~kg}^{\text {tree }}{ }^{-1}$ for citrus in Iran [8] and $1.2 \mathrm{~kg}$ tree $^{-1}$ for 'Maltaise' citrus in Tunisia [11]. These were slightly inferior to the figure $1.15 \mathrm{~kg}$ tree $^{-1}$ in this study for Navel orange, because more $\mathrm{K}$ would carry the risk of environmental pollution and nutrient leaching.

Citrus trees are evergreen trees that grow year-round, have a long fruit-bearing period, and, thus, have a high demand for nutrients. Organic fertilizers, which have stable fertilization efficiency, can continuously meet the nutrient demand for the yearround growth of citrus trees, and for this reason are more conducive to the development of fruit quality. This study showed that OM5+K20-treated Newhall navel orange trees had the highest yield, indicating that combined potassium and organic fertilizer application 
can improve Newhall navel orange growth. The results of this study show that combined potassium and organic fertilizer application significantly reduces pericarp thickness, which improves fruit coloration and intrinsic fruit quality; these findings are consistent with the results of Ashraf [14].

\section{Conclusions}

Combined potassium and organic fertilizer application can quickly meet the nu-trient requirements of Newhall navel orange trees at different growth stages, which promotes the accumulation of nutrients in the autumn shoots. It also promotes the sprouting of spring shoots and nutrient uptake, thus increasing the Newhall navel or-ange yield and fruit size, improving fruit coloration, reducing pericarp thickness, in-creasing the TSS content, TSS/TA ratio, and Vitamin C content in fruits, as well as de-creasing the TA content. Therefore, combined potassium and organic fertilizer appli-cation is recommended for citrus orchards with purple paddy soil in southwestern China. The recommended doses of organic and potassium sulfate fertilizers for Newhall navel orange orchards with purple paddy soil in southwestern China are $5-10 \mathrm{~kg} /$ plant and 1.15-1.20 kg/plant, respectively.

Author Contributions: M.W. have made substantial contributions to the conception, design of the work, drafting the work, revising it critically for important intellectual content. J.Z. contributed to the acquisition, analysis, and interpretation of data for the work. Y.Z. contributed to the final approval of the version to be published. S.Y. contributed to the agreement to be accountable for all aspects of the work in ensuring that questions related to the accuracy orintegrity of any part of the work are appropriately investigated and resolved. All authors have read and agreed to the published version of the manuscript.

Funding: This research was funded by the Technology Innovation and Application Development project in Chongqing (No. cstc2020jscx-msxmX0026), National Key Research and development project (No. 2018YFD0700602, 2016YFD0200104 and 2020YFD1000101).

Data Availability Statement: The data used to support the findings of this study are available from the corresponding author upon request.

Conflicts of Interest: The authors declare no conflict of interest.

\section{References}

1. Sardans, J.; Peñuelas, J. Potassium Control of Plant Functions: Ecological and Agricultural Implications. Plants 2021, 10, 419. [CrossRef]

2. Popova, O.V.; Golldack, D. In the halotolerant Lobularia maritima (Brassicaceae) salt adaptation correlates with activation of the vacuolar $\mathrm{H}^{+}$-ATPase and the vacuolar $\mathrm{Na}^{+} / \mathrm{H}^{+}$antiporter. J. Plant Physiol. 2007, 10, 1278-1288. [CrossRef]

3. Lester, G.E.; Jifon, J.L.; Rogers, G. Supplemental foliar potassium applications during muskmelon fruit development can improve fruit quality, ascorbic acid, and beta-carotene contents. J. Am. Soc. Hortic. Sci. 2005, 4, 649-653. [CrossRef]

4. Cakmak, I.; Atli, M.; Kaya, R.; Evliya, H.; Marschner, H. Association of high light and zinc deficiency cold induced leaf chlorosis in grapefruit and mandarin trees. J. Plant Physiol. 1995, 3, 355-360. [CrossRef]

5. Gimeno, V.; Díaz-Lopez, L.; Simon-Grao, S.; Martínez, V.; Martínez-Nicoas, J.J.; García-Sanchez, F. Foliar potassium nitrate application improves the tolerance of Citrus macrophylla L. seedlings to drought conditions. Plant Physiol. Biochem. 2014, 83, 308-315. [CrossRef] [PubMed]

6. Tiwari, K.N. Diagnosing potassium deficiency and maximizing fruit crop production. Better Crop. 2005, 4, 29-31.

7. Alva, A.K.; Tucker, D. Soil and citrus nutrition. In Citrus Health Management; Gainesville University of Florida: Gainesville, FL, USA, 1999; pp. 59-71.

8. Ashkevari, A.; Hossein, Z.; Miransari, M. Potassium fertilization and fruit production of page citrus on a punsirus rootstock: Quantitative and qualitative traits. J. Plant Nutr. 2010, 10, 1564-1578. [CrossRef]

9. Hartz, T.K.; Johnstone, P.R.; Francis, D.M.; Miyao, E.M. Processing tomato yield and fruit quality improved with potassium fertigation. HortScience 2005, 6, 1862-1867. [CrossRef]

10. Liu, K.; Zhang, T.Q.; Tan, C.S.; Astatkie, T. Responses of fruit yield and quality of processing tomato to drip-irrigation and fertilizers phosphorus and potassium. Agronomy 2011, 5, 1339-1345. [CrossRef]

11. Ben Mimoun, M.; Dbara, S.; Lahmar, K.; Marchand, M. Effects of potassium nutrition on fruit yield and quality of 'maltaise' citrus (citrus sinensis L.). Acta Hortic. 2018, 1217, 225-230. [CrossRef]

12. Ruiz, R. Effects of different potassium fertilizers on yield, fruit quality and nutritional status of fairlane nectarine trees and on soil fertility. Acta Hortic. 2006, 721, 185-190. [CrossRef] 
13. Mengel, K. Impact of potassium on crop yield and quality with regard to economical and ecological aspects. In Food Security in the WANA Region: The Essential Need for Balanced Fertilization; Johnston, A.E., Ed.; International Potash Institute: Bornova, Turkey, 1997; pp. 157-174.

14. Ashraf, M.Y.; Gul, A.; Ashraf, M.; Hussain, F.; Ebert, G. Improvement in yield and quality of kinnow (citrus deliciosa $\times$ citrus nobilis) by potassium fertilization. J. Plant Nutr. 2010, 11, 1625-1637. [CrossRef]

15. Alexander, P.D.; Bragg, N.C.; Meade, R.; Padelopoulos, G.; Watts, O. Peat in horticulture and conservation: The UK response to a changing world. Mires Peat. 2008, 3, 1-10.

16. Dahlin, J.; Nelles, M.; Herbes, C. Biogas digestate management: Evaluating the attitudes and perceptions of German gardeners towards digestate-based soil amendments. Resour. Conserv. Recycl. 2017, 118, 27-38. [CrossRef]

17. Möller, K.; Schultheiß, U. Chemical characterization of commercial organic fertilizers. Arch. Agron. Soil Sci. 2014, 7, 989-1012. [CrossRef]

18. Toma, Y.; Higuchu, T.; Nagata, O.; Kato, Y.; Izumiya, T.; Oomori, S.; Ueno, H. Efflux of soil nitrous oxide from applied fertilizer containing organic materials in citrus unshiu field in southwestern japan. Agriculture 2017, 7, 10. [CrossRef]

19. Dheware, R.M.; Waghmare, M.S. Influence of organic-inorganic and biofertilizers and their interactions on flowering and fruitset of sweet orange (Citrus sinesis osbeck L.). Asian J. Hortic. 2009, 4, 194-197.

20. Du, S.P.; Ma, Z.M.; Xue, L. Effects of different kinds of organic fertilizer on fruit yield, quality and nutrient uptake of watermelon in gravel-mulched field. J. Appl. Ecol. 2019, 4, 1269-1277.

21. Bao, S.D. Soil Agrochemical Analysis, 3rd ed.; China Agriculture Press: Beijing, China, 2000; pp. 263-270. (In Chinese)

22. Cline, J.A.; Trought, M. Effect of gibberellic acid on fruit cracking and quality of Bing and Sam sweet cherries. Can. J. Plant Sci. 2007, 3, 545-550. [CrossRef]

23. Xu, Q.X.; Wang, T.W.; Cai, C.F.; Li, Z.X.; Shi, Z.H. Effects of soil conservation on soil properties of citrus orchards in the Three-Gorges Area, China. Land Degrad Dev. 2010, 1, 34-42. [CrossRef]

24. Heena, N.P.; Rafiya, L.; Rashid, S.; Nisar, B.; Kamili, A.N. Chemical Fertilizers and Their Impact on Soil Health. Microbiota Biofertil. 2021, 2, 1-29.

25. Wang, X.L.; Zhang, S.Q.; Chen, Y.L.; Palta, J. Chemical fertilizer applied in combination with organic manure promoted maize (Zea mays L.) yield and water use efficiency in a semi-arid region of China. In Proceedings of the 7th International Crop Science Congress, Beijing, China, 14-19 August 2016.

26. Srivastava, A.K. Integrated Nutrient Management in Citrus. Adv. Citrus Nutr. 2012, 369-389. [CrossRef]

27. Dahunsi, S.O.; Oranusi, S.; Efeovbokhan, V.E.; Adesulu-Dahunsi, A.T.; Ogunwole, J.O. Crop performance and soil fertility improvement using organic fertilizer produced from valorization of carica papaya fruit peel. Sci. Rep. 2021, 1, 4696. [CrossRef]

28. Shaviv, A. Advances in controlled-release fertilizers. Adv. Agron. 2001, 1, 1-49. [CrossRef]

29. Kennedy, A.C.; Smith, K.L. Soil microbial diversity and sustainability of agricultural soils. Plant Soil. 1995, 170, 75-86. [CrossRef]

30. Deeken, R.D.; Geiger, J.F.; Koroleva, O.; Ache, P.; Langenfeld-Heyserj, R.; Sauer, N.; May, S.T.; Hedrich, R. Loss of the AKT2/3 potassium channel affects sugar loading into the phloem of Arabidopsis. Planta 2002, 216, 334-344. [CrossRef] [PubMed]

31. Smith, H.M.; Samach, A. Constraints to obtaining consistent annual yields in perennial tree crops. I: Heavy fruit load dominates over vegetative growth. Plant Sci. 2013, 207, 158-167. [CrossRef]

32. Omaima, M.H.; Metwally, I.M. Efficiency of zinc and potassium spray alone or in combination with some weed control treatments on weed growth yield and fruit quality of Washington navel oranges. J. Appl. Sci. Res. 2007, 3, 613-621.

33. Tatti, E.; Goyer, C.; Zebarth, B.J.; Viti, C.D.; Burton, L. Short-term effects of mineral and organic fertilizer on denitrifiers, nitrous oxide emissions and denitrification in long-term amended vineyard soils. Soil Sci. Soc. Am. J. 2013, 1, 113-122. [CrossRef]

34. Lester, G.E.; Manthey, J.A.; Buslig, B.S. Organic vs conventionally grown rio red whole grapefruit and juice: Comparison of production inputs, market quality, consumer acceptance, and human health-bioactive compounds. J. Agric. Food Chem. 2007, 11, 74-80. [CrossRef]

35. Ashraf, M.Y.; Hussain, F.; Ashraf, M.; Akhter, J.; Ebert, G. Modulation in yield and juice quality characteristics of citrus fruit from trees supplied with zinc and potassium foliarly. J. Plant Nutr. 2013, 13, 1996-2012. [CrossRef] 